\title{
Immunomodulation for the Treatment of Fungal Infections: Opportunities and Challenges
}

\author{
Muluneh Ademe* \\ Department of Microbiology, Immunology and Parasitology, College of Health Sciences, Addis Ababa University, Addis \\ Ababa, Ethiopia
}

OPEN ACCESS

Edited by:

Yong-Sun Bahn,

Yonsei University, South Korea

Reviewed by:

Ping Wang,

Louisiana State University,

United States

Jill R. Blankenship, University of Nebraska Omaha,

United States

*Correspondence:

Muluneh Ademe

muluneh.ademe@aau.edu.et

Specialty section:

This article was submitted to

Fungal Pathogenesis,

a section of the journal

Frontiers in Cellular and Infection

Microbiology

Received: 08 June 2020

Accepted: 30 July 2020

Published: 15 September 2020

Citation:

Ademe M (2020) Immunomodulation for the Treatment of Fungal Infections:

Opportunities and Challenges.

Front. Cell. Infect. Microbiol. 10:469.

doi: 10.3389/fcimb.2020.00469
Opportunistic fungal infections are major causes of morbidity and mortality in patients with single or multiple defects in their immunity. Antifungal agents targeting the pathogen remain the treatment of choice for fungal infections. However, antifungal agents are toxic to the host mainly due to the close evolutionary similarity of fungi and humans. Moreover, antifungal therapy is ineffective in patients with immunosuppression. For this reason, there is an increased demand to develop novel strategies to enhance immune function and augment the existing antifungal drugs. In recent times, targeting the immune system to improve impaired host immune responses becomes a reasonable approach to improve the effectiveness of antifungal drugs. In this regard, immunomodulating therapeutic agents that turn up the immune response in the fight against fungal infections hold promise for enhancing the efficacy and safety of conventional antifungal therapy. In general, immunomodulating therapies are safe with decreased risk of resistance and broad spectrum of activity. In this review, therefore, clinical evidences supporting the opportunities and challenges of immunomodulation therapies in the treatment of invasive fungal infections are included.

\section{Keywords: immunomodulation, fungal infections, antifungal therapy, cytokine therapy, cellular therapy}

\section{INTRODUCTION}

Fungi cause a variety of clinical infections which range from asymptomatic-mild infections to potentially life-threatening systemic infections (Brown et al., 2012). Over the past few decades, the prevalence of fungal infections increased dramatically mainly due to the AIDS epidemics, irrational use of broad-spectrum antibiotics, the widespread use of intravascular catheters, advances in surgery and organ transplantation, and the increasing immune suppression (Segal et al., 2006; Rodloff et al., 2011). Each year, about 11.5 million life-threatening infections and more than 1.5 million deaths occur due to fungal infections (Bongomin et al., 2017).

Antifungal agents targeting the pathogen such as polyenes, azoles, flucytosine, and echinocandins are the treatment of choice for most fungal infections. However, the side effects associated with the use of antifungal agents, the appearance of resistant fungal strains, varied spectra of activity and failure to sterilize infected organs seriously limit the efficacy of antifungal chemotherapy (Neofytos et al., 2009). Particularly in severely immunosuppressed patients, response to systemic antifungal therapy alone remains disproportionately less satisfactory and cure may be improved if the immune deficit remits (Brown et al., 2012; Safdar, 2013). Currently, immunomodulating therapeutic agents that target the host immune response hold promise for improving conventional antifungal therapy (Casadevall and Pirofski, 2001). However, there is 
limited data concerning the benefit and clinical effectiveness of immunomodulation as an adjunct to antifungal therapy. Therefore, in this review, clinical evidences supporting the opportunities and challenges of immunomodulation therapies in the treatment of invasive fungal infections are discussed.

\section{IMMUNOMODULATING THERAPIES FOR FUNGAL INFECTIONS}

The lower burden of fungal infections in people with intact immune response has been taken as strong evidence that normal immunity mediates effective resistance to fungal infections (Casadevall and Pirofski, 2001). In this regard, targeting the immune system to augment impaired host immune responses and thus enhance the efficacy of antifungal drugs becomes a reasonable approach to improve the prognosis of fungal infections (Casadevall and Pirofski, 2001; Segal et al., 2006). Immunomodulation, therefore, refers to a range of treatments aimed at harnessing patients' immune system to achieve control, stabilization, and potential eradication of disease (Sam et al., 2018). As mentioned below and summarized in Table 1, several immunomodulating approaches have been clinically tested for the treatment of fungal infections.

\section{Adoptive T-Cell Therapy}

Adoptive T-cell therapy involves harvesting of T-lymphocytes from a patient or donor's blood, stimulating the cells to grow and expand in an in vitro system, and subsequently re-infusing the cells back into the patient. In this technique, high numbers of specific T-cells are injected into the patient where they recognize their target and aid the immune system in its elimination (Papadopoulou et al., 2016). Adoptive T-cell therapy is usually used after allogeneic stem cell transplantation (allo-SCT) because the adaptive immune system reconstitutes much slower than the innate immune system and artificial increase of specific T-cells helps to clear fungal infections (Bacher et al., 2015).

Adoptive therapy using in vitro-expanded fungus-specific $\mathrm{T}$ cells has shown clinical efficacy in murine and human clinical studies. As reviewed in Deo et al. the use of Apsergillus-specific $\mathrm{CD} 4+\mathrm{T}$ cells isolated from the spleens of immunized mice which were re-stimulated in vitro were protective and extended the life of mice (Deo and Gottlieb, 2015). In a clinical trial by Perruccio et al. ten haploidentical stem cell transplant recipients with evidence of invasive aspergillosis received a single infusion of $1 \times 10^{5}-1 \times 10^{6}$ cells per kg of expanded donor-derived antiAspergillus T-cell clones, and 9 of 10 patients cleared the infection within $7.8 \pm 3.4$ weeks (Perruccio et al., 2005).

Adoptive cell therapy is a promising tool for the fight against fungal infections. However, generating an adequate number of fungal-specific T-cells with sufficient purity as per

Abbreviations: ADCC, Antibody-dependent cell mediated cytotoxicity; allo SCT, Allogeneic hematopoietic stem cell transplantation; CAR, Chimeric antigen receptor; CDC, complement dependent cytotoxicity; CSFs, Colony-stimulating factors; G-CSF, Granulocyte Colony-Stimulating Factor; GM-CSF, GranulocyteMacrophage Colony-Stimulating Factor; M-CSF, Macrophage colony-stimulating factors; MHC, Major Histocompatibility Complex. the guidelines of Good Manufacturing Practice (GMP) is the major limitation (Papadopoulou et al., 2016). Moreover, certain immunosuppressants which are frequently used after allo-SCT such as cyclosporine A, methylprednisolone, and mycophenolic acid may interfere with adoptive T-cell transfer by lowering the number and activation of specific protective Th1 cells (Tramsen et al., 2014).

\section{Chimeric Antigen Receptor (CAR) T-Cell Therapy}

CARs are artificially designed receptors that are introduced into T-cells. The CAR modification allows T-cells to execute their killing command without the need to bind to other receptors (Meiliana et al., 2016). CAR T-cell therapies were approved by the U.S. FDA for use in cancer (FDA news release, 2017), and the success of CAR T-cells in B cell malignancies led to the attempt to use CARs for infections including fungal diseases. Dectin-1, a naturally occurring receptor of the innate immune system that is not expressed on T-cells, has been targeted for CAR therapy. $ß$ glucan, the ligand for Dectin-1, is a polysaccharide found on the surface of many fungi (Lauruschkat et al., 2018). Kumaresan et al. constructed a CAR T-cell adapting the fungal receptor Dectin-1 for Aspergillus to activate T-cells via chimeric CD28 and CD3$\zeta$. In this study, the Dectin-CAR was activated by $ß$-glucan and the growth of Aspergillus fumigatus was inhibited (Kumaresan et al., 2014). CAR T-cells are one of the most promising immunotherapeutic tools and major histocompatibility complex (MHC) unrestricted antigen recognition is the main advantage of CAR T-Cell therapy. In recent times, repurposing T-cells through CAR T-cell therapy becomes an active area of research in the fight against infections and hematological malignancies. However, this therapeutic approach may provoke cytokine release syndrome (CRS) and neurotoxicity (Kochenderfer et al., 2012; Brudno and Kochenderfer, 2016). Moreover, the autologous generation of sufficient numbers of CAR T-cells may take several weeks, which might lose critical time in an acute infection like invasive fungal infections (Neelapu et al., 2017). Allogeneic CAR T-cell therapy, on the other hand, may give rise to off-the-shelf products with decreased cost and it can also be suitable for many patients as opposed to autologous CAR T-cell therapy in which each treatment must be made individually for each patient (Depil et al., 2020). Yet, allogeneic CAR T cells may cause life-threatening graft-vs.-host disease (GvHD), and these allogeneic T cells may also be rapidly eliminated by the host immune system, limiting their intended activity (Depil et al., 2020).

\section{Granulocyte Transfusion}

Patients with leukemia or undergoing haematopoietic stem cell transplant (HSCT) are at higher risk of acquiring fungal infections (Grow et al., 2002). Prolonged neutropenia has become a major risk factor of invasive fungal infections and the spectrum of infections in neutropenic patients has shifted, with invasive fungal infections emerging as major determinants of morbidity and mortality (Marr et al., 2002). Without correction of neutropenia, antifungals alone may not resolve infections against which neutrophils form the primary line of defense. Therefore, in cases of drug-resistant fungal infections, granulocyte transfusion 
TABLE 1 | Clinical benefits and challenges of immunomodulating agents used in patients with fungal infections.

\begin{tabular}{|c|c|}
\hline Immunomodulating Agents & Clinical Benefit \\
\hline Adoptive T-cell therapy & $\begin{array}{l}\text { Stimulation of T-cells with antigen and infusion into the patient } \\
\text { (Tramsen et al., 2014) }\end{array}$ \\
\hline Monoclonal antibodies & $\begin{array}{l}\text { Avoid toxicity risks because they are directed specifically to } \\
\text { pathogen epitopes, reduce durations of antifungal drug } \\
\text { treatment (Casadevall et al., 2004; Cassone, 2008) }\end{array}$ \\
\hline CAR T-cell therapies & $\begin{array}{l}\text { T-cells are genetically modified to express CAR and provide } \\
\text { MHC unrestricted antigen recognition (Meiliana et al., 2016) }\end{array}$ \\
\hline Dendritic Cells (DCs) & $\begin{array}{l}\text { Leads to activation of specific T-cells and secretion of } \\
\text { cytokines and chemokines. It can be used both in } \\
\text { immunotherapy and vaccination (Lauruschkat et al., 2018) }\end{array}$ \\
\hline G-CSF & Restores neutrophil counts (Wright et al., 2017) \\
\hline GM-CSF & $\begin{array}{l}\text { Stimulates proliferation and differentiation of hematopoietic } \\
\text { progenitor cells. Enhances antimicrobial function of mature } \\
\text { neutrophils and monocytes against fungal targets (Safdar } \\
\text { et al., 2013). It has wide range of applications (Shiomi and } \\
\text { Usui, 2015) }\end{array}$ \\
\hline Granulocyte Transfusion & $\begin{array}{l}\text { Increases neutrophil counts, augments the host's defenses } \\
\text { and reverses the increased susceptibility to infections (Hickey } \\
\text { and Kubes, 2009) }\end{array}$ \\
\hline IFN- & $\begin{array}{l}\text { Enhance Th1 response and augments the antifungal activity } \\
\text { of macrophages and neutrophils (Stevens et al., 2006) }\end{array}$ \\
\hline Interleukins & $\begin{array}{l}\text { Enhance Th1-mediated immunity (Winn et al., 2003; Akdis } \\
\text { et al., 2011) }\end{array}$ \\
\hline M-CSF & $\begin{array}{l}\text { Promotes the growth of macrophages, increases } \\
\text { phagocytosis, chemotaxis, and secondary cytokine } \\
\text { production in monocytes and macrophages (Kandalla et al., } \\
\text { 2016) }\end{array}$ \\
\hline NK cell therapy & $\begin{array}{l}\text { Release soluble factors (such as IFN- } \gamma \text { ) which mediate } \\
\text { antifungal activity. It may have activity against a wide } \\
\text { spectrum of fungi (Schneider et al., 2016) }\end{array}$ \\
\hline $\begin{array}{l}\text { Pathogen recognition receptors } \\
\text { (TLR and PTX3) }\end{array}$ & $\begin{array}{l}\text { Recognize motifs on fungal species and induce inflammatory } \\
\text { responses. It is useful for TLR-defective individuals (Netea } \\
\text { et al., 2006) }\end{array}$ \\
\hline TNF- $\alpha$ & Stimulates PMNs (Lauruschkat et al., 2018) \\
\hline
\end{tabular}

Challenges

Generation of an adequate number of fungal-specific T cells with sufficient purity is challenging (Papadopoulou et al., 2016)

Highly specific, high production costs (Chames et al., 2009)

Cytokine release syndrome and neurotoxicity (Kochenderfer et al., 2012; Brudno and Kochenderfer, 2016), longer time needed to generate autologous CAR T-cells (Neelapu et al., 2017), allogeneic T-cells may cause GvHD, and may be rapidly eliminated by the host immune system (Depil et al., 2020)

Cost inefficient, difficult to scale, and labor intensive (Lauruschkat et al., 2018)

Lineage-specific (Costa, 1998), may stimulate leukemia (Rowe, 2000)

Faster depletion, less stability and low targeting efficiency (Vanitha et al., 2017), may stimulate leukemia (Rowe, 2000)

Limited success due to low granulocyte counts and short lifespan of granulocytes (Estcourt et al., 2016; West et al., 2017)

Potential to induce exacerbation of tissue inflammation, ischemia, and necrosis (Safdar et al., 2005), may worsen GvHD in allogeneic HSCT recipients (Wang et al., 2009)

Unintended deleterious effects (Casadevall and Pirofski, 2001)

In cancer patients, it may worsen disease progression by enhancing macrophage population (Medina-Echeverz et al., 2014)

As shown in malignancies, evasion from NK cells control may limit the success of NK cell therapy (Davies et al., 2014)

Difficult for manufacturing on a commercial scale, complex and unpredictable mode of action (Zeromski et al., 2019)

Hepatotoxicity, nephrotoxicity, and neurotoxicity after systemic administration (Lauruschkat et al., 2018)

remains a logically attractive solution. Granulocytes engulf fungus, release antimicrobial peptides, and form extracellular traps (West et al., 2017). Granulocyte transfusion theoretically increases neutrophil counts, augments the host's defenses and reverses the increased susceptibility to infections (Hickey and Kubes, 2009).

The potential for leucocyte transfusion was established by early animal studies. In 1953, Brecher et al. showed that granulocytes transfused to neutropenic dogs migrated to areas of infection (Brecher et al., 1953). Since then, different studies supported the efficacy of granulocyte transfusion in invasive fungal infections. In a retrospective review by Diaz et al. $80 \%$ of children with granulocyte dysfunction or severe neutropenia who received granulocyte transfusion demonstrated response to invasive fungal infections (Díaz et al., 2014). Furthermore, among pediatric HSCT recipients treated with granulocyte transfusion, seven out of 14 patients with invasive fungal infections showed radiological improvement, with 79\% 100day survival (Nikolajeva et al., 2015). As reviewed by West et al. granulocyte transfusion together with granulocyte colonystimulating factors (G-CSFs) yielded an overall response rate of $50-90 \%$ in invasive fungal diseases (West et al., 2017). However, the overall success of granulocyte transfusion is limited due to low granulocyte counts, low quality and short lifespan of the granulocytes (Estcourt et al., 2016; West et al., 2017).

\section{Dendritic Cells (DCs) Therapy}

Dendritic cells recognize fungus by pattern recognition receptors and process fungal antigens. Activated dendritic cells secrete cytokines and chemokines, migrate to the lymph nodes and present antigens to specific $\mathrm{T}$ cells, which in turn are activated and primed (Bozza et al., 2003). In this approach, DCs can be 
stimulated with fungal antigens ex vivo and transfused to the patient. These DCs induce protective immune responses to the fungus due to activation of fungus-specific $\mathrm{T}$ cells (Roy and Klein, 2012). In a mouse model by Shao et al. DCs that had been transduced with IL-12 and stimulated by $A$. fumigatus were administered to neutropenic mice, and the DC therapy led to decreased mortality and fungal burden due to a strong Th1 response (Shao et al., 2005). Likewise, in a murine model, protective Th1 response was found when DCs were stimulated by A. fumigatus conidia and transfected with IL-12 (Bozza et al., 2003). However, despite the therapeutic potential of ex vivo DC stimulation in fungal infection, administration to the human patient is thought to be cost inefficient, difficult to scale, and labor intensive (Lauruschkat et al., 2018).

\section{Natural Killer (NK) Cell Therapy}

NK cell therapy involves the transfer of NK cells from a donor to a patient. NK cells are the most significant contributor to IFN$\gamma$ secretion (Wang et al., 2012). Indeed, NK cell therapy is in its trial stage and data are scarce pertaining to its application in fungal infections. However, available reports showed that NK cell therapy has an immunotherapeutic potential against a wide spectrum of fungi, including Aspergillus fumigatus, Cryptococcus neoformans, Rhizopus oryzae, Candida albicans, Paracoccidioides brasiliensis, and Mucorales (Schneider et al., 2016). For instance, in allo-SCT patients, increased NK cell counts were associated with better control of invasive aspergillosis (Stuehler et al., 2015).

\section{Cytokine Therapy}

Strengthening the immune system through administration of cytokines is the other approach to fight fungal infections. Cytokines modulate the immune response of the host by acting as signaling molecules that specifically induce the proliferation, differentiation, and activation or suppression of different target cells (Gulati et al., 2016). For instance, neutropenia predisposes cancer patients on corticosteroids to invasive fungal infections. Cytokines will shorten the duration of neutropenia by enhancing the phagocytic and killing activities of neutrophils, monocytes, and macrophages (Chiou et al., 2000; Winn et al., 2003). Cytokines used as immunomodulatory agents in fungal infection include colony-stimulating factors (CSFs), Interferon-Gamma (IFN- $\gamma)$, TNF $\alpha$ and Interleukins.

\section{Interferon-Gamma (IFN- $\gamma$ )}

Interferon-gamma (IFN- $\gamma$ ) skews the immune response toward a protective Th1 phenotype. IFN- $\gamma$ has been implicated as a treatment option in invasive fungal infections (Stevens et al., 2006). IFN- $\gamma$ therapy was shown to augment the antifungal activity by significantly increasing the numbers of macrophages and neutrophils (Stevens et al., 2006; Lehrnbecher et al., 2011). In a randomized controlled trial on HIV positive patients with Cryptococcus meningitis, Jarvis and colleagues compared the addition of IFN- $\gamma$ to standard amphotericin B therapy. In this study, Jarvis et al. showed that short-course IFN- $\gamma$ therapy significantly increased the rate of CSF Cryptococcus clearance, with no significant increase in adverse events (Jarvis et al., 2012). Delsing et al. also recruited eight patients with invasive Candida and/or Aspergillus infections and administered IFN- $\gamma$ together with standard antifungal therapy. In their finding, five of the eight patients treated with IFN- $\gamma$ recovered from the invasive fungal disease (Delsing et al., 2014). Furthermore, three patients on renal transplant who were suffering from disseminated invasive aspergillosis were cured after 6 weeks of combined amphotericin $\mathrm{B}$ and IFN- $\gamma$ treatment (Armstrong-James et al., 2010). A recent case report by Tsai and colleagues revealed that a child with life-threatening disseminated coccidioidomycosis had shown a reduced production of interferon- $\gamma$. The child was treated with interferon- $\gamma$ together with antifungal therapy, and the treatment augmented type 1 immunity and resulted in complete resolution of the disease (Tsai et al., 2020). However, IFN- $\gamma$ therapy in allogeneic hematopoietic stem cell transplant recipients may potentially worsen GvHD (Wang et al., 2009).

\section{Tumor Necrosis Factor $\alpha$ (TNF- $\alpha$ )}

TNF- $\alpha$ stimulates polymorphonuclear neutrophils (PMNs), which in turn increase oxygen radical release and cause enhanced hyphal damage against fungal infections (Lauruschkat et al., 2018). In an earlier study by Nagai et al. administration of TNF- $\alpha$ to immunosuppressed mice in a model for pulmonary aspergillosis increased survival (Nagai et al., 1995). Moreover, in a mice model by Mehrad et al. intra-tracheal challenge with $A$. fumigatus conidia in both neutropenic and nonneutropenic BALB/c mice increased lung TNF- $\alpha$ levels. This also correlated with infiltration of mononuclear and polymorphonuclear cells (Mehrad et al., 1999). In the same study, neutralization of TNF- $\alpha$ caused an increase in lung fungal burden and mortality in both normal and neutropenic mice (Mehrad et al., 1999). However, toxicity following systemic administration, including hepatotoxicity, nephrotoxicity, and neurotoxicity are major limitations of TNF- $\alpha$ therapy (Lauruschkat et al., 2018).

\section{Interleukins}

Interleukins are known to enhance Th1-mediated immunity which is essential for the protection against fungal pathogens (Akdis et al., 2011). For instance, IL-12 production is strongly correlated with the development of Th1 immunity through inhibition of Th2 type cellular responses which enhances host defense. In mice with neutropenia, IL-12 enhanced fluconazole efficacy against Candida infections. Moreover, IL-12 alone was shown to have an activity in experimental murine cryptococcosis, histoplasmosis, aspergillosis, and coccidioidomycosis (Mencacci et al., 2000; Winn et al., 2003). However, in human patients with autologous bone marrow transplants, 2 of 12 patients developed fatal fungal infections after IL-12 therapy. This event raised the concern that IL-12 administration may have unintended deleterious effects on immune function (Casadevall and Pirofski, 2001).

\section{Colony-Stimulating Factors (CSFs)}

CSFs are secreted glycoproteins which bind to receptor proteins on the surfaces of hemopoietic stem cells. Through activation of intracellular signaling pathways, CSFs promote proliferation and differentiation of cells into a specific kind of blood cell (Sionov 
and Segal, 2003). CSFs are mostly used to accelerate myelopoiesis and augment phagocyte function. CSFs, including Macrophage CSF (M-CSF), G-CSF, and Granulocyte-Macrophage ColonyStimulating Factor (GM-CSF) are used as immunomodulating agents for the treatment of fungal infections (Sionov and Segal, 2003; Sionov et al., 2005).

M-CSF promotes the growth of macrophages, increases phagocytosis, chemotaxis, and secondary cytokine production in monocytes and macrophages (Kandalla et al., 2016). M-CSF has been shown to be used for the treatment of fungal infections as adjunct therapy with other conventional antifungal agents. Kandalla et al. treated transplant-mouse models with M-CSF and found improved survival of the mice when challenged with A. fumigatus, from $10 \%$ in controls to $60 \%$ in M-CSF treated mice (Kandalla et al., 2016). On the other study by Hume and MacDonald, 46 stem cell transplantation patients with invasive fungal disease were given recombinant human M-CSF with conventional antifungal treatment, and patients who received $\mathrm{M}$ CSF showed better survival as compared to historical controls (27 and 5\%, respectively) (Hume and MacDonald, 2012). However, as tumor-associated macrophages represent up to $50 \%$ of the tumor cell mass in cancer patients, administration of M-CSF may accelerate disease progression by enhancing the macrophage population (Medina-Echeverz et al., 2014). In this regard, M-CSF is not usually recommended to be used in cancer patients with fungal infections.

G-CSF, on the other hand, promotes survival, proliferation, and differentiation of all cells in the neutrophil lineage. Plus, G-CSFs increase the function of mature neutrophils (Roberts, 2005). As chemotherapy may be myelo-suppressive causing neutropenia, G-CSF can be used adjunctly with conventional antifungal agents to restore neutrophil counts. In the study by Grigull et al. three children with proven fungal infections and hematological malignancies were treated with combination of G-CSF and antifungal therapy. The combination therapy effectively treated the fungal infection and all children survived both the underlying malignancy and the fungal infection (Grigull et al., 2006). Moreover, in HIV-infected patients with Aspergillus hyphae, G-CSF was shown to reverse neutrophil dysfunction (Wright et al., 2017).

While G-CSF is relatively lineage-specific, GM-CSF stimulates a wider range of immune cells (Costa, 1998). GM-CSF stimulates maturation of dendritic cells from monocyte precursors, differentiation of macrophages, and proliferation and activation of macrophages, monocytes, neutrophils, eosinophils, dendritic cells, and microglia (Shiomi and Usui, 2015). In this regard, GM-CSF has a theoretical advantage against wide range of fungal pathogens for which host defense is dependent on both neutrophil and macrophage function (Shiomi and Usui, 2015; Scriven et al., 2017). In a study by Giles et al. prophylaxis with GM-CSF for patients receiving chemotherapy to treat acute myelogenous leukemia led to a lower frequency of fatal fungal infections (1.9\%) as compared to placebo (19\%) (Giles, 1998). Chen et al. also examined the role of GM-CSF in patients with Aspergillus ventriculitis which has a high mortality (67\%) with conventional treatment. In this study, GM-CSF was given as adjunct therapy in conjunction with voriconazole, amphotericin
B, and caspofungin. After 2 years of therapy, patients fully recovered and remained in remission (Chen et al., 2017).

CSFs can be administered separately or in combinations with one or more CSFs. However, a better efficacy in reducing fungal disease incidence was reported when two or more CSFs are given combined with antifungal agents (Kuhara et al., 2000). For instance, in a clinical trial, Wan et al. compared the effect of prophylactic treatment of 206 allogenic HSCT recipients with G-CSF, GM-CSF, or a combination of both (G-CSF + GM$\mathrm{CSF})$. Their findings showed that invasive fungal disease related mortality after 600 days was lower in the groups who received G-CSF+GM-CSF (1.45\%) or GM-CSF (1.47\%) compared with G-CSF (11.59\%) $(P=0.016)$ (Wan et al., 2015).

\section{MONOCLONAL ANTIBODIES}

The efficacy of therapeutic antibodies stems from various natural functions of antibodies including neutralization, antibodydependent cell mediated cytotoxicity (ADCC,) and complement dependent cytotoxicity (CDC). Moreover, the antibody can be utilized as a drug delivery carrier (Suzuki et al., 2015). Humoral response is important for the host defense against fungal infections. Antibodies activate the classical pathway of the complement system and complement activation leads to the killing of fungi by neutrophils. In this regard, monoclonal antibodies (mAbs) can be used for immunotherapeutic purposes (Casadevall and Pirofski, 2012). Mycograb, for instance, is a human recombinant monoclonal antibody that was revealed to have synergy when combined with fluconazole, caspofungin, and amphotericin B against a broad spectrum of Candida species (Bugli et al., 2013). In a murine model, Matthews et al. tested the therapeutic potential of Mycograb with a combination of standard antifungal therapy, amphotericin B. Their findings showed a high overall response rate of Mycograb (84\%) compared to controls (49\%). The overall Candida-related mortality was also reduced from 18 (controls) to $4 \%$ (Mycograb) (Matthews et al., 2003). Rudkin et al. also generated a human recombinant anti- Candida mAbs (Rudkin et al., 2018). According to the report, the binding of $\mathrm{mAb}$ to $C$. albicans cell surface antigens promotes Fc $\gamma \mathrm{R}$ dependent phagocytosis by macrophages, and it resulted in a reduced fungal burden in a murine model of disseminated candidiasis (Rudkin et al., 2018). Furthermore, a 4-year-old child with life-threatening disseminated coccidioidomycosis was observed to have an exaggerated production of interleukin-4. The child was treated with dupilumab, a monoclonal antibody that blocks the alpha chain common to the interleukin4 and interleukin-13 receptors, and it resulted in rapid resolution of the clinical symptoms (Tsai et al., 2020). Moreover, as reviewed in Boniche et al. using monoclonal antibody-based immunomodulation therapies was shown to have a promising therapeutic potential over a wide range of fungal infections, including, Histoplasma capsulatum, Aspergillus fumigatus, Pneumocystis jirovecii, Cryptococcus neoformans, Sporothrix schenckii, and Blastomyces dermatitidis (Boniche et al., 2020). However, the majority of clinically utilized mAbs 
are chimeric, humanized or, fully human IgG1, produced by hybridoma technology, and the production of these mABs demands good manufacturing practice (GMP) conditions (Strohl, 2014; Rudkin et al., 2018). Moreover, the high production costs and high specificity restrain the extended use of mAbs (Chames et al., 2009).

\section{Toll-Like Receptors (TLRs)}

Host immunity to recognize and respond to the fungal pathogen is mediated by a range of pathogen recognition receptors (PRRs) including TLRs (TLRs 2, 4, 7, 9). TLRs recognize motifs on fungal species and regulate the induced inflammatory responses (Plato et al., 2015). In view of this, TLR4 defective mice were shown to be more susceptible to $C$. albicans infection which is attributed to chemokine expression and neutrophil recruitment (Netea et al., 2006). These conceptions pave the way for the use of TLR agonists for the treatment of fungal infections which doesn't respond well in conventional antifungal treatments. In the study by Erbagci et al. an immunocompetent healthy patient who had lesions on her face for over 20 years caused by Acremonium strictum and which was unresponsive to topical and systemic antifungals was successfully treated with a TLR-7 agonist (topical imiquimod) (Erbagci et al., 2005).

\section{Pentraxin-3 (PTX3)}

PTX3 is a pentraxin-related protein which is encoded by the PTX3 gene in humans. It is produced and released by different cells, including dendritic cells (DCs), mononuclear phagocytes, endothelial cells, and fibroblasts in response to primary inflammatory signals (Kunes et al., 2012). PTX3 enables pathogen recognition by macrophages and DCs through activation of the classical pathway of the complement system. PTX3 binds with high affinity to selected microorganisms, including A. fumigatus. In this regard, increased risk of fungal infections has been associated with deficiency of PTX3 (Daigo et al., 2016). In murine model, Pentraxin 3 deficient mice demonstrated defective recognition of conidia by alveolar macrophages and dendritic cells and they were highly susceptible to Aspergillus infection. Then again, administration of pentraxin 3 protected against Aspergillus challenge (Garlanda et al., 2002). Furthermore, in allogenic stem cell transplantation patients, the increased risk of invasive aspergillosis was linked to genetic deficiency of PTX3 (Cunha et al., 2014). While encouraging, the application of PRRs faces certain hurdles. On one hand, these natural products are usually polymeric, and unsuitable for manufacturing on a commercial scale. On the other hand, the mode of action is often complex and the effects in living organisms are unpredictable (Zeromski et al., 2019).

\section{REFERENCES}

Akdis, M., Burgler, S., Crameri, R., Eiwegger, T., Fujita, H., and Gomez, E. (2011). Interleukins, from 1 to 37, and interferon-g: receptors, functions, and roles in diseases. J. Allergy Clin Immunol. 127, 701-721. doi: 10.1016/j.jaci.2010.11.050

\section{CHALLENGES OF IMMUNOMODULATION THERAPY}

The number of anti-fungal resistant isolates is increasing and conventional antifungal drugs can have severe side effects to the host. Conversely, immunomodulating agents, in general, are reported to be safe with decreased risk of resistance and broad spectrum of activity (Lauruschkat et al., 2018; Sam et al., 2018). However, despite all the promising benefits, immunomodulation therapies used for treating fungal infections are still exploratory which involves complex as well as timeintensive genetic and cellular manipulations before use. Much more work has to be done to prove its efficacy in human trials (Lauruschkat et al., 2018).

Immunomodulation therapies are also cost-intensive, and the high costs may prohibit many patients from receiving this potentially life-saving therapy, especially patients located in the developing world where the burdens of fungal infections are expected to be high (Segal et al., 2006). Furthermore, immunomodulating therapies might sometimes be accompanied by severe side effects, such as toxicities, and inflammation. Pro-inflammatory cytokines, for instance, are essential to the host as mediators of inflammation and host resistance to infections. However, their overexpression leads to local and systemic toxicity (Netea et al., 2006). Likewise, administration of recombinant human G-CSF in A. fumigatus infected outbred mice antagonized the action of SCH56592 azole derivative, and resulted in large lung abscesses with increased fungal burden (Graybill et al., 1998).

\section{CONCLUSION}

Immunomodulation approaches hold promise for improving the efficacy of antifungal therapy, subsequently decreasing the morbidity and mortality due to fungal infections. However, the use of immunomodulating agents to combat fungal infections is at the exploratory stage. To the date this review was done, most of imunomodulating agentstargeted for the treatment of fungal infections in humans are under clinical trials. However, considering the revolution of immunotherapies in treating cancer, immunomodulation may have the potential to become a game changer in the treatment of fungal infections, perhaps in the foreseeable future.

\section{AUTHOR CONTRIBUTIONS}

MA contributed to conception, design, acquisition, analysis and interpretation of data, and took part in drafting and revising the article. All authors contributed to the article and approved the submitted version. 
Bacher, P., Jochheim-Richter, A., Mockel-Tenbrink, N., Kniemeyer, O., Wingenfeld, E., Alex, R., et al. (2015). Clinical-scale isolation of the total Aspergillus fumigatus-reactive T-helper cell repertoire for adoptive transfer. Cytotherapy. 17, 1396-1405. doi: 10.1016/j.jcyt.2015.05.011

Bongomin, F., Gago, S., Oladele, R. O., and Denning, D. W. (2017). Global and multi-national prevalence of fungal diseases-estimate precision. J Fungi 3, 1-29. doi: 10.3390/jof3040057

Boniche, C., Rossi, S. A., Kischkel, B., Barbalho, F. V., D'Aurea Moura, A., Nosanchuk, D., et al. (2020). Immunotherapy against systemic fungal infections based on monoclonal antibodies. J Fungi. 6, 1-28. doi: 10.3390/jof6010031

Bozza, S., Perruccio, K., Montagnoli, C., Gaziano, R., Bellocchio, S., Burchielli, E., et al. (2003). A dendritic cell vaccine against invasive aspergillosis in allogeneic hematopoietic transplantation. Blood 102, 3807-3814. doi: 10.1182/blood-2003-03-0748

Brecher, G., Wilbur, K. M., and Cronkite, E. P. (1953). Transfusion of separated leukocytes into irradiated dogs with aplastic marrows. Proc. Soc. Exp. Biol. Med. 84, 54-56. doi: 10.3181/00379727-84-20539

Brown, G. D., Denning, D. W., Gow, N. A., Levitz, S. M., Netea, M. G., and White, T. C. (2012). Hidden killers: human fungal infections. Sci. Transl. Med. 4, 1-9. doi: 10.1126/scitranslmed.3004404

Brudno, J. N., and Kochenderfer, J. N. (2016). Toxicities of chimeric antigen receptor $\mathrm{T}$ cells: recognition and management. Blood 127, 3321-3330. doi: 10.1182/blood-2016-04-703751

Bugli, F., Cacaci, M., Martini, C., Torelli, R., Posteraro, B., Sanguinetti, M., et al. (2013). Human monoclonal antibody-based therapy in the treatment of invasive candidiasis. Clin Dev Immunol. 2013:403121. doi: $10.1155 / 2013 / 403121$

Casadevall, A., Dadachova, E., and Pirofski, L. A. (2004). Passive antibody therapy for infectious diseases. Nat. Rev. Microbiol. 2, 695-703. doi: $10.1038 /$ nrmicro974

Casadevall, A., and Pirofski, L. (2001). Adjunctive immune therapy for fungal infections. Clin Infect Dis. 33, 1048-1056. doi: 10.1086/322710

Casadevall, A., and Pirofski, L. (2012). Immunoglobulins in defense, pathogenesis, and therapy of fungal diseases. Cell Host Microbe 11, 447-456. doi: 10.1016/j.chom.2012.04.004

Cassone, A. (2008). Fungal vaccines: real progress from real challenges. Lancet Infect. Dis. 8, 114-124. doi: 10.1016/S1473-3099(08)70016-1

Chames, P., Van Regenmortel, M., Weiss, E., and Baty, D. (2009). Therapeutic antibodies: successes, limitations and hopes for the future. Brt. J. Pharmacol. 157, 220-233. doi: 10.1111/j.1476-5381.2009.00190.x

Chen, T. K., Groncy, P. K., Javahery, R., Chai, R. Y., Nagpala, P., Finkelman, M., et al. (2017). Successful treatment of Aspergillus ventriculitis through voriconazole adaptive pharmacotherapy, immunomodulation, and therapeutic monitoring of cerebrospinal fluid (1rightarrow3)-b-D-glucan. Med Mycol. 55, 109-117. doi: 10.1093/mmy/myw118

Chiou, C. C., Groll, A. H., and Walsh, T. J. (2000). New drugs and novel targets for treatment of invasive fungal infections in patients with cancer. Oncologist 5, 120-135. doi: 10.1634/theoncologist.5-2-120

Costa, J. J. (1998). The therapeutic use of hematopoietic growth factors. J Allergy Clin Immunol. 101, 1-6. doi: 10.1016/S0091-6749(98)70185-X

Cunha, C., Aversa, F., Lacerda, J. F., Busca, A., Kurzai, O., Grube, M., et al. (2014). Genetic PTX3 deficiency and aspergillosis in stem-cell transplantation. N. Engl. J. Med. 370, 421-432. doi: 10.1056/NEJMoa1211161

Daigo, K., Inforzato, A., Barajon, I., Garlanda, C., Bottazzi, B., Meri, S., et al. (2016). Pentraxins in the activation and regulation of innate immunity. Immunol Rev. 274, 202-217. doi: 10.1111/imr.12476

Davies, J. O. J., Stringaris, K., Barrett, J. A., and Rezvani, K. (2014). Opportunities and limitations of NK cells as adoptive therapy for malignant disease. Cytotherapy 16, 1453-1466. doi: 10.1016/j.jcyt.2014.03.009

Delsing, C. E., Gresnigt, M. S., Leentjens, J., Preijers, F., Frager, F. A., Kox, M., et al. (2014). Interferon-gamma as adjunctive immunotherapy for invasive fungal infections: a case series. BMC Infect. Dis. 14, 1-12. doi: 10.1186/1471-2334-14-166

Deo, S. S., and Gottlieb, D. J. (2015). Adoptive T-cell therapy for fungal infections in haematology patients. Clin. Transl. Immunol. 4, 1-7. doi: 10.1038/cti.2015.16

Depil, S., Duchateau, P., Grupp, S. A., Mufti, G., and Poirot, L. (2020). 'Off-theshelf' allogeneic CAR T cells: development and challenges. Nat. Rev. Drug Discov. 19, 185-199. doi: 10.1038/s41573-019-0051-2
Díaz, R., Soundar, E., Hartman, S. K., Dreyer, Z., Teruya, J., and Hui, S. K. (2014). Granulocyte transfusions for children with infection and neutropenia or granulocyte dysfunction. Pediatr. Hematol. Oncol. 31, 425-434. doi: $10.3109 / 08880018.2013 .868562$

Erbagci, Z., Tuncel, A. A., Erkilic, S., and Zer, Y. (2005). Successful treatment of antifungal- and cryotherapy-resistant subcutaneous hyalohyphomycosis in an immunocompetent case with topical 5\% imiquimod cream. Mycopathologia 159, 521-526. doi: 10.1007/s11046-005-5260-z

Estcourt, L. J., Stanworth, S. J., Hopewell, S., Doree, C., Trivella, M., and Massey, E. (2016). Granulocyte transfusions for treating infections in people with neutropenia or neutrophil dysfunction. Cochrane Database Syst Rev. 4, 1-76. doi: 10.1002/14651858.CD005339.pub2

FDA news release (2017). FDA Approves CAR-T Cell Therapy to Treat Adults With Certain Types of Large B-Cell Lymphoma. Available online at: https://www. fda.gov/news-events/press-announcements/fda-approves-car-t-cell-therapytreat-adults-certain-types-large-b-cell-lymphoma. (accessed on 3 June, 2020).

Garlanda, C., Hirsch, E., Bozza, S., Salustri, A., De Acetis, M., Nota, R., et al. (2002). Non-redundant role of the long pentraxin PTX3 in anti-fungal innate immune response. Nature 420, 182-186. doi: 10.1038/nature01195

Giles, F. J. (1998). Monocyte-macrophages, granulocyte-macrophage colonystimulating factor, and prolonged survival among patients with acute myeloid leukemia and stem cell transplants. Clin. Infect. Dis. 26, 1282-1289. doi: $10.1086 / 516361$

Graybill, J. R., Bocanegra, R., Najvar, L. K., Leobenberg, D., and Luther, M. F. (1998). Granulocyte colony stimulating factor and azole antifungal therapy in murine aspergillosis: role of immune suppression. Antimicrob. Agents Chemother. 42, 2467-2473. doi: 10.1128/AAC.42.10.2467

Grigull, L., Beilken, A., Schmid, H., Kirschner, P., Sykora, K. W., Linderkamp, C., et al. (2006). Secondary prophylaxis of invasive fungal infections with combination antifungal therapy and G-CSF-mobilized granulocyte transfusions in three children with hematological malignancies. Support Care Cancer 14, 783-786. doi: 10.1007/s00520-005-0910-8

Grow, W. B., Moreb, J. S., Roque, D., Manion, K., Leather, H., Reddy, V., et al. (2002). Late onset invasive Aspergillus infection in bone marrow transplant patients at a University hospital. Bone Marrow Transplant. 29, 15-19. doi: $10.1038 /$ s..bmt. 1703332

Gulati, K., Guhathakurta, S., Joshi, J., Rai, N., and Ray, A. (2016). Cytokines and their role in health and disease: a brief overview. MOJ Immunol. 4, 1-9. doi: $10.15406 /$ moji.2016.04.00121

Hickey, M. J., and Kubes, P. (2009). Intravascular immunity: the hostpathogen encounter in blood vessels. Nat. Rev. Immunol. 9, 364-375. doi: $10.1038 /$ nri2532

Hume, D. A., and MacDonald, K. P. (2012). Therapeutic applications of macrophage colony-stimulating factor-1 (CSF-1) and antagonists of CSF-1 receptor (CSF-1R) signaling. Blood 119, 1810-1820. doi: 10.1182/blood-2011-09-379214

Jarvis, J. N., Meintjes, G., Rebe, K., Williams, G. N., Bicanic, T., Williams, A., et al. (2012). Adjunctive Interferon-g immunotherapy for the treatment of HIV associated cryptococcal meningitis: a randomized controlled trial. AIDS 26, 1105-1113. doi: 10.1097/QAD.0b013e3283536a93

Kandalla, P. K., Sarrazin, S., Molawi, K., Berruyer, C., Redelberger, D., Favel, A., et al. (2016). M-CSF improves protection against bacterial and fungal infections after hematopoietic stem/progenitor cell transplantation. J. Exp. Med. 213, 2269-2279. doi: 10.1084/jem.20151975

Kochenderfer, J. N., Dudley, M. E., Feldman, S. A., Wilson, W. H., Spaner, D. E., Maric, I., et al. (2012). B-cell depletion and remissions of malignancy along with cytokine-associated toxicity in a clinical trial of antiCD19 chimeric-antigen-receptor-transduced T cells. Blood 119, 2709-2720. doi: 10.1182/blood-2011-10-384388

Kuhara, T., Uchida, K., and Yamaguchi, H. (2000). Therapeutic efficacy of human macrophage colony-stimulating factor, used alone and in combination with antifungal agents, in mice with systemic Candida Albicans Infection. Antimicrob. Agents Chemother. 44, 19-23. doi: 10.1128/AAC.44.1.19-23. 2000

Kumaresan, P. R., Manuri, P. R., Albert, N. D., Maiti, S., Singh, H., Mi, T., et al. (2014). Bioengineering $\mathrm{T}$ cells to target carbohydrate to treat opportunistic fungal infection. Proc. Natl. Acad. Sci. U.S.A. 111, 10660-10665. doi: $10.1073 /$ pnas.1312789111 
Kunes, P., Holubcova, Z., Kolackova, M., and Krejsek, J. (2012). Pentraxin 3(PTX 3): an endogenous modulator of the inflammatory response. Mediat Inflamm. 2012:10. doi: 10.1155/2012/920517

Lauruschkat, C. D., Einsele, H., and Loeffler, J. (2018). Immunomodulation as a therapy for aspergillus infection: current status and future perspectives. $J$. Fungi. 4:137. doi: 10.3390/jof4040137

Lehrnbecher, T., Tramsen, L., Koehl, U., Schmidt, S., Bochennek, K., and Klingebiel, T. (2011). Immunotherapy against invasive fungal diseases in stem cell transplant recipients. Immunol. Invest. 40, 839-852. doi: 10.3109/08820139.2011.581732

Marr, K. A., Carter, R. A., Crippa, F., Wald, A., and Corey, L. (2002). Epidemiology and outcome of mould infections in hematopoietic stem cell transplant recipients. Clin. Infect. Dis. 34, 909-917. doi: 10.1086/339202

Matthews, R. C., Rigg, G., Hodgetts, S., Carter, T., Chapman, C., Gregory, C., et al. (2003). Preclinical assessment of the efficacy of mycograb, a human recombinant antibody against fungal HSP90. Antimicrob. Agents Chemother. 47, 2208-2216. doi: 10.1128/AAC.47.7.2208-2216.2003

Medina-Echeverz, J., Aranda, F., and Berraondo, P. (2014). Myeloid-derived cells are key targets of tumor immunotherapy. Oncoimmunology 3:e28398. doi: 10.4161/onci.28398

Mehrad, B., Strieter, R. M., and Standiford, T. J. (1999). Role of TNF-alpha in pulmonary host defense in murine invasive aspergillosis. J Immunol. 162, 1633-1640.

Meiliana, A., Dewi, M. N., and Wijaya, A. (2016). Cancer immunotherapy: a review. Indones Biomed J. 8, 1-20. doi: 10.18585/inabj.v8i1.189

Mencacci, A., Cenci, E., Bacci, A., Bistoni, F., and Romani, L. (2000). Host immune reactivity determines the efficacy of combination immunotherapy and antifungal chemotherapy in candidiasis. J. Infect. Dis. 181, 686-694. doi: $10.1086 / 315277$

Nagai, H., Guo, J., Choi, H., and Kurup, V. (1995). Interferon-gamma and tumor necrosis factor-alpha protect mice from invasive aspergillosis. J. Infect. Dis. 172, 1554-1560. doi: 10.1093/infdis/172.6.1554

Neelapu, S. S., Locke, F. L., Bartlett, N. L., Lekakis, L. J., Miklos, D. B., Jacobson, C. A., et al. (2017). Axicabtagene ciloleucel CAR T-cell therapy in refractory large B-cell lymphoma. N. Engl. J. Med. 377, 2531-2544. doi: 10.1056/NEJMoa1707447

Neofytos, D., Horn, D., Anaissie, E., Steinbach, W., Olyaei, A., Fishman, J., et al. (2009). Epidemiology and outcome of invasive fungal infection in adult hematopoietic stem cell transplant recipients: analysis of multicenter prospective antifungal therapy (PATH) alliance registry. Clin. Infect. Dis. 48, 265-273. doi: 10.1086/595846

Netea, M. G., Ferwerda, G., van der Graaf, C. A., Van der Meer, J. W., and Kullberg, B. J. (2006). Recognition of fungal pathogens by toll-like receptors. Curr. Pharm. Des. 12, 4195-4201. doi: 10.2174/138161206778743538

Nikolajeva, O., Mijovic, A., Hess, D., Tatam, E., Amrolia, P., Chiesa, R., et al. (2015). Single-donor granulocyte transfusions for improving the outcome of highrisk pediatric patients with known bacterial and fungal infections undergoing stem cell transplantation: a 10-year single-centre experience. Bone Marrow Transplantation. 50, 846-849. doi: 10.1038/bmt.2015.53

Papadopoulou, A., Kaloyannidis, P., Yannaki, E., and Cruz, C. R. (2016). Adoptive transfer of Aspergillus-specific $\mathrm{T}$ cells as a novel anti-fungal therapy for hematopoietic stem cell transplant recipients: progress and challenges. Crit. Rev. Oncol Hematol. 98, 62-72. doi: 10.1016/j.critrevonc.2015.10.005

Perruccio, K., Tosti, A., Burchielli, E., Topini, F., Ruggeri, L., Carotti, A., et al. (2005). Transferring functional immune responses to pathogens after haploidentical hematopoietic transplantation. Blood 106, 4397-4406. doi: 10.1182/blood-2005-05-1775

Plato, A., Hardison, S. E., and Brown, G. D. (2015). Pattern recognition receptors in antifungal immunity. Semin. Immunopathol. 37, 97-106. doi: 10.1007/s00281-014-0462-4

Roberts, A. W. (2005). G-CSF: a key regulator of neutrophil production, but that's not all! Growth Factors 23, 33-41. doi: 10.1080/08977190500055836

Rodloff, C., Koch, D., and Schaumann, R. (2011). Epidemiology and antifungal resistance in invasive candidiasis. Eur. J. Med. Res. 16, 187-195. doi: $10.1186 / 2047-783 \mathrm{X}-16-4-187$

Rowe, J. M. (2000). Concurrent use of growth factors and chemotherapy in acute leukemia. Curr. Opin. Hematol. 7, 197-202. doi: 10.1097/00062752-200005000-00012
Roy, R. M., and Klein, B. S. (2012). Dendritic cells in antifungal immunity and vaccine design. Cell Host Microbe 11, 436-446. doi: 10.1016/j.chom.2012.04.005

Rudkin, F. M., Raziunaite, I., Workman, H., Essono, S., Belmonte, R., and MacCallum, D. M. (2018). Single human B cell-derived monoclonal antiCandida antibodies enhance phagocytosis and protect against disseminated candidiasis. Nat. Commun. 9:5288. doi: 10.1038/s41467-018-07738-1

Safdar, A. (2013). Immunotherapy for invasive mold disease in severely immunosuppressed patients. Clin Infect Dis. 57, 94-100. doi: 10.1093/cid/cit187

Safdar, A., Rodriguez, G., Ohmagari, N., Kontoyiannis, D. P., Rolston, K. V., Raad I. I., et al. (2005). The safety of interferongamma-1b therapy for invasive fungal infections after hematopoietic stem cell transplantation. Cancer 103, 731-739. doi: $10.1002 /$ cncr.20883

Safdar, A., Rodriguez, G., Zuniga, J., Al Akhrass, F., Georgescu, G., and Pande, A. (2013). Granulocyte macrophage colony stimulating factor in 66 patients with myeloid or lymphoid neoplasms and recipients of hematopoietic stem cell transplantation with invasive fungal disease. Acta Haematol. 129, 26-34. doi: 10.1159/000342121

Sam, Q. H., Yew, W. S., Seneviratne, C. J., Chang, M. W., and Chai, L. Y. A. (2018). Immunomodulation as therapy for fungal infection: are we closer? Front. Microbiol. 9:1612. doi: 10.3389/fmicb.2018.01612

Schneider, A., Blatzer, M., Posch, W., Schubert, R., Lass-Flörl, C., Schmidt, S., et al. (2016). Aspergillus fumigatus responds to natural killer (NK) cells with upregulation of stress related genes and inhibits the immunoregulatory function of NK cells. Oncotarget 7, 71062-71071. doi: 10.18632/oncotarget.12616

Scriven, J. E., Tenforde, M. W., Levitz, S. M., and Jarvis, J. N. (2017). Modulating host immune responses to fight invasive fungal infections. Curr. Opin. Microbiol. 40, 95-103. doi: 10.1016/j.mib.2017.10.018

Segal, B. H., Kwon-Chung, J., Walsh, T. J., Klein, B. S., Battiwalla, M., Almyroudis, N. G., et al. (2006). Immunotherapy for fungal infections. Clin Infect Dis. 42, 507-515. doi: 10.1086/499811

Shao, H. J., Chen, L., and Su, Y. B. (2005). DNA fragment encoding human IL1beta 163-171 peptide enhances the immune responses elicited in mice by DNA vaccine against foot-and-mouth disease. Vet. Res. Commun. 29, 35-46. doi: 10.1023/B:VERC.0000046743.27552.19

Shiomi, A., and Usui, T. (2015). Pivotal roles of GM-CSF in autoimmunity and inflammation. Mediat Inflamm. 2015:568543. doi: 10.1155/2015/568543

Sionov, E., Mendlovic, S., and Segal, E. (2005). Experimental systemic murine aspergillosis: treatment with polyene and caspofungin combination and GCSF. J. Antimicrob. Chemother. 56, 594-597. doi: 10.1093/jac/dki252

Sionov, E., and Segal, E. (2003). Polyene and cytokine treatment of experimental aspergillosis. FEMS Immunol Med Microbiol. 39, 221-227. doi: 10.1016/S0928-8244(03)00230-X

Stevens, D. A., Brummer, E., and Clemons, K. V. (2006). Interferon- gamma as an antifungal. J. Infect. Dis. 194, S33-S37. doi: 10.1086/505357

Strohl, W. R. (2014). Antibody discovery: sourcing of monoclonal antibody variable domains. Curr. Drug. Discov. Technol. 11, 3-19. doi: 10.2174/1570163810666131120150043

Stuehler, C., Kuenzli, E., Jaeger, V. K., Baettig, V., Ferracin, F., Rajacic, Z., et al. (2015). Immune reconstitution after allogeneic hematopoietic stem cell transplantation and association with occurrence and outcome of invasive aspergillosis. J. Infect. Dis. 212, 959-967. doi: 10.1093/infdis/jiv143

Suzuki, M., Kato, C., and Kato, A. (2015). Therapeutic antibodies: their mechanisms of action and the pathological findings they induce in toxicity studies. J. Toxicol. Pathol. 28, 133-139. doi: 10.1293/tox.2015-0031

Tramsen, L., Schmidt, S., Roeger, F., Schubert, R., Salzmann-Manrique, E., Latge, J. P., et al. (2014). Immunosuppressive compounds exhibit particular effects on functional properties of human anti-Aspergillus Th1 cells. Infect Immun. 82, 2649-2656. doi: 10.1128/IAI.01700-14

Tsai, M., Thauland, T. J., Huang, A. Y., Bun, C., Fitzwater, S., Krogstad, P., et al. (2020). Disseminated coccidioidomycosis treated with interferon- $\gamma$ and Dupilumab. N. Engl. J. Med. 382, 2337-2343. doi: 10.1056/NEJMoa2000024

Vanitha, S., Chaubey, N., Ghosh, S. S., and Sanpui, P. (2017). Recombinant human granulocyte macrophage colony stimulating factor (hGM-CSF): possibility of nanoparticle-mediated delivery in cancer immunotherapy. Bioengineered 8, 120-123. doi: 10.1080/21655979.2016.1212136

Wan, L., Zhang, Y., Lai, Y., Jiang, M., Song, Y., Zhou, J., et al. (2015). Effect of granulocyte-macrophage colony-stimulating factor on prevention 
and treatment of invasive fungal disease in recipients of allogeneic stem-cell transplantation: a prospective multicenter randomized phase IV trial. J. Clin. Oncol. 33, 3999-4006. doi: 10.1200/JCO.2014.60.5121

Wang, H., Asavaroengchai, W., Yeap, B. Y., Wang, M., Wang, S., and Sykes, M. (2009). Paradoxical effects of IFN- $\gamma$ in graft-versus-host disease reflect promotion of lymphohematopoietic graft-versus-host reactions and inhibition of epithelial tissue injury. Blood 113, 3612-3619. doi: 10.1182/blood-2008-07-168419

Wang, R., Jaw, J. J., Stutzman, N. C., Zou, Z., and Sun, P. D. (2012). Natural killer cell-produced IFN- $\gamma$ and TNF- $\alpha$ induce target cell cytolysis through up-regulation of ICAM-1. J. Leukoc. Biol. 91, 299-309. doi: 10.1189/jlb.0611308

West, K. A., Gea-Banacloche, J., Stroncek, D., and Kadri, S. S. (2017). Granulocyte transfusions in the management of invasive fungal infections. Br. J. Haematol. 177, 357-374. doi: 10.1111/bjh.14597

Winn, R. M., Gil-Lamaignere, C., Roilides, E., Simitsopoulou, M., Lyman, C. A., Maloukou, A., et al. (2003). Selective effects of interleukin (IL)-15 on antifungal activity and IL-8 release by polymorphonuclear leukocytes in response to hyphae of Aspergillus species. J. Infect. Dis. 188, 585-590. doi: 10.1086/377099
Wright, C. R., Ward, A. C., and Russell, A. P. (2017). Granulocyte colonystimulating factor and its potential application for skeletal muscle repair and regeneration. Mediat. Inflamm. 2017:7517350. doi: 10.1155/2017/7517350

Zeromski, J., Kaczmarek M, Boruczkowski, M., Kierepa, A., Kowala-Piaskowska, A., Mozer-Lisewska, I., (2019). Significance and role of pattern recognition receptors in malignancy. Archivum Immunol et Ther Exp. 67, 133-141. doi: 10.1007/s00005-019-00540-x

Conflict of Interest: The author declares that the research was conducted in the absence of any commercial or financial relationships that could be construed as a potential conflict of interest.

Copyright (C) 2020 Ademe. This is an open-access article distributed under the terms of the Creative Commons Attribution License (CC BY). The use, distribution or reproduction in other forums is permitted, provided the original author(s) and the copyright owner(s) are credited and that the original publication in this journal is cited, in accordance with accepted academic practice. No use, distribution or reproduction is permitted which does not comply with these terms. 